\title{
Investment is the best cure for inbreeding
}

\author{
Lack of funding and difficulty in setting up new labs encourage researchers to stay put.
}

Sir-M. Soler in Correspondence ("How inbreeding affects productivity in Europe", Nature 411, 132; 2001) quantifies endogamy, or "inbreeding", in 14 European countries as the percentage of staff trained at the same university. His results are of great value as a basis for political decisions on university reform. He discovered a huge variation in endogamy, from $1 \%$ in Germany to $88 \%$ in Spain and 91\% in Portugal. To uncover the causes, I have analysed some economic and demographic data published in the Eurostat Yearbook 2001 (Eurostat, Luxembourg, 2001; http://europa.eu.int/ comm/eurostat/Public).

The percentage of GDP invested in research and development is significantly negatively correlated with endogamy $\left(r_{\mathrm{s}}=-0.75, P=0.0018\right)$. In terms of annual per capita investment in R\&D, Portugal (67 euros; US\$60.6) and Spain (116 euros) invest the least, and Sweden (936 euros) and Switzerland (935 euros) the most, with the remaining countries showing intermediate values. This indicates that endogamy is a consequence of poor investment policies.

Because there has been much discussion about Spain, I will refer to it here as an example. Spain is the secondhighest country in Soler's endogamy index, but has the lowest cost per paper appearing in the Science Citation Index (SCI). This leads one to ask whether endogamy is indeed negative for the R\&D system?

To answer this question, I calculated three indexes of productivity. One is simply the number of SCI papers per capita, which is negatively correlated with endogamy $\left(r_{\mathrm{s}}=-0.73, P=0.003\right)$. The second is the number of $S C I$ papers per researcher. I obtained the number of researchers (including technicians) per country (except the United Kingdom and Germany) from the World Bank web page (http://wbln0018.worldbank.org/psd/ compete.nsf/f14ea5988b0eec7f852564900 $068 \mathrm{cbfd}$ ?OpenView). This second index fails to show significant correlation with endogamy $\left(r_{s}=-0.17, P=0.59\right)$. My third index is the cost per paper appearing in the $S C I$, calculated as the quotient between the absolute amount of money invested in $\mathrm{R} \& \mathrm{D}$ and the number of papers appearing in the SCI. This index also failed to show significant correlation with endogamy $\left(r_{\mathrm{s}}=-0.37, P=0.19\right)$.

Taken as a whole, these results could reflect the unequal numbers of researchers per 10,000 inhabitants, varying from 1 in Spain and Portugal to 6 in Sweden, and perhaps the different effort demanded of researchers in different countries.

In my opinion, Spanish endogamy is caused by low investment in R\&D (0.9\% of GDP in 1999). Spanish universities lack research technicians, so researchers have to do everything: collecting materials in the field, preparing samples for analysis, performing all laboratory techniques, and so on, as well as teaching. Spanish SCI papers are thus low-cost, but single researchers have very difficult lives, impelling us to integrate into groups for support - a process which is also encouraged by the policies of regional governments. On average, we need 10 or more years to create a research group with acceptable productivity.

Moving is very difficult for many reasons, some discussed by previous correspondents. Those who do move have to start a new lab from scratch with no equipment and without colleagues from the previous lab. The logical consequence of these factors is reluctance to move, and hence endogamy.

I agree with Soler and other correspondents that this situation needs to be corrected. My analysis shows that the best and simplest solution for Spain is significantly increased investment in $R \& D$, which would avoid the causes of endogamy. But I am afraid that the government's proposed reform is opting for the cheapest solution, not the best one. Juan Pedro M. Camacho

Department of Genetics, Faculty of Science, University of Granada, E-18071 Granada, Spain

\section{Taxonomy is small, but it has its citation classics}

Sir - F. T. Krell in Correspondence

("Impact factors aren't relevant to taxonomy”, Nature 405, 507-508, 2000) suggests that taxonomy is subject to different "regularities" from other fields. He uses the allegedly small number of entomology, biodiversity and taxonomy journals covered in the Science Citation Index $(S C I)$ as the reason for low impact factors. But he provides only anecdotal data on the size of this literature. How many articles are published by the lowimpact journals at the Natural History Museum?

Krell refers to Bradford's law of scattering, but he needs instead to provide data to show that entomology-taxonomy diversity is somehow different from other fields. Bradford's law simply suggests that if there are, say, 1,000 journals in a field, then one-third of the papers are to be found in each of three zones containing about 10, 100 and 1,000 journals, respectively.

A critical element in determining the impact factor of a field is not the number of papers it publishes, but the citation density of the average paper and the halflife of the references cited. Adding more journals to the SCI database would not increase the impact because the increased number of cited references would have to be shared by more published papers.

The data on the 65 entomology journals covered in the SCI indicate that their impact factors are not significantly different from other fields with long halflives (see the Institute for Scientific Information's Journal Citation Reports, http://www.isinet.com/isi/products/ citation/jcr/?version=1). However, the size of a field does affect the number of super-cited papers that will be published.

Krell states: "Qualified referees must evaluate the scientific work itself." But this is equally true of any field. Why shouldn't such evaluation be supplemented by citation analysis? The question is whether the referee has any basis for comparing articles, authors or journals across a wider horizon. Taxonomy, small as it may be, is not without its 'citation classics', as the work of R. Sokal, E. O. Wilson and others demonstrates. Their work is cited by thousands of papers covered in the SCI, by taxonomists and by other scientists.

Eugene Garfield

Institute for Scientific Information, 3501 Market Street, Philadelphia, Pennsylvania 19104, USA

\section{Ethical link between IVF and stem-cell research}

Sir - I fully support your editorial "The meaning of life” (Nature 412, 255; 2001), in which you argue that individual life does not begin with fertilization of the egg and that it thus should not be used as an argument against creating embryonic stem cells, which requires the destruction of fertilized embryos. Hubert Markl's Commentary "Research doesn't denigrate humanity" (Nature 412, 479-480; 2001) makes a similar point. 
However, I regret that you missed the opportunity to point out that human reproduction by in vitro fertilization (IVF) also involves the fertilization of the egg and the early development of the embryo, and that large numbers of such embryos are destroyed.

There is thus no ethical difference between IVF and creating embryonic stem cells, as both require the creation and destruction of embryos. One can be, for religious reasons, against both, but not rationally against one and not the other. IVF has been of enormous value and so too will stem cells.

\section{Lewis Wolpert}

Department of Anatomy and Developmental Biology, University College London, Gower Street, London WC1E 6BT, UK

\section{Science archives should remain in public hands}

Sir - We would like to correct any impression of neglect of Britain's rich scientific archive heritage that might have been given by the News feature "The History Man", about the US private collector Jeremy Norman (Nature 411, 732; 2001). On the contrary, the United Kingdom is fortunate in having universities and national institutions that show an active interest in collecting science archives.

The Royal Society and the Wellcome Trust, for example, have supported the preservation and cataloguing of such materials over many years. The Wellcome Trust has recently established a Research Resources in Medical History scheme, with $\mathfrak{E} 1$ million (\$US1.4 million) for the year 2001-2002 to support important documentary collections.

Archives in universities, including contemporary science archives, have benefited from major funding programmes run by the Higher Education Funding Councils. A recent award from the UK Heritage Lottery Fund will allow a group of science institutions to mount a large number of catalogues of scientists' archives on the web as part of Access to Archives, a vast online catalogue at http://www.a2a.pro.gov.uk.

Many important personal scientific papers are held in libraries and repositories in the United Kingdom, some having been catalogued by the National Cataloguing Unit for the Archives of Contemporary Scientists (NCUACS). This work is supported by several scientific societies, trusts and foundations, preserving a significant part of contemporary British science and biomedicine in a major collaborative effort.
For the long-term benefit, such papers are best housed in properly resourced public repositories in their country of origin, rather than in private hands.

Archivists, who will always have to struggle to maintain their budgets in a competitive world, will be greatly helped by widespread recognition of that basic principle. Peter Harper ${ }^{\star}$, Julia Sheppard $\dagger$ ${ }^{*}$ NCUACS, University Library, University of Bath, Claverton Down, Bath BA2 7AY, UK †Wellcome Library, 183 Euston Road, London NW1 2BE, UK

\section{Nature's laws revealed in rhyming couplets}

Sir - I would like to add to Fleming Carswell's interesting Correspondence (Nature 411, 885; 2001) about the relevance of poetry to scientists today by mentioning a few of the scientists who in the past published their work as poetry.

Charles Darwin's grandfather Erasmus Darwin (1731-1802), for example, wrote up some of his own evolutionary and other theories in Popean couplets, perhaps best known in The Temple of Nature:

Organic life beneath the shoreless waves Was born and nurs'd in Ocean's pearly caves;

First forms minute, unseen by spheric glass,

Move on the mud, or pierce the watery

mass.

In the same poem he describes 'the Maiden Truffle' as an example of reproduction without a sexual partner:

So the lone Truffle, lodged beneath the earth,

Shoots from paternal stems the tuberous birth.

No stamen-males ascend, and breathe

above,

No seed-born offspring lives by female

love.

These influenced not only his grandson but also the English romantic poets, to such an extent that Samuel Coleridge used the term "Darwinizing" to describe such poetic theorizing.

Alexander Pope (1688-1744) himself asked a cosmological question in his Essay on Man, Epistle 1, which is only now being answered:

Observe how System into System runs.

What other Planets circle other Suns?

Later in the same epistle, he seemed to lay the foundation of statistics:

All Nature is but Art unknown to thee;

All Chance, Direction which thou canst

not see.

Pope also wrote in his Epitaph for Sir Isaac Newton (perhaps anticipating the need for this journal?):
Nature, and Nature's laws lay hid in night

God said, Let Newton be! and all was light.

to which J. C. Squire (1884-1958) in his Epigrams replied:

It did not last: the Devil howling " $\mathrm{Ho!}$

Let Einstein be!", restored the status quo.

The advice Pope gave in his Essay on Criticism could apply to Nature's referees:

Let such teach others who themselves excel And censure freely who have written well.

Modern poets offer yet more of the stimulating and enjoyable reasons why, as Carswell states, scientists should "bother about poetry". Not least among these are the poetry of Edwin Morgan (to be found, for example, in Stargate, Third Eye Centre, Glasgow, 1979); Miroslav Holub (for example, Vanishing Lung Syndrome, Faber and Faber, London, 1990); and Ronald Duncan (for example, Man: The Complete Cantos, Rebel Press, London, 1970).

\section{N. C. Craig Sharp}

Department of Sport Sciences, Brunel University, Borough Road, Isleworth, Middlesex TW7 5DU, UK

\section{Enthusiasm ran ahead of discoveries still to come}

Sir - In your excellent News story "Epidemiology gains an ally in bioweapons surveillance project" (Nature 411, 228; 2001), summarizing the rapid syndrome validation project (RSVP) for early 'syndrome-based' epidemiological reporting, you faithfully reported my statement that "This rapid reporting already appears to have this year averted two outbreaks of hepatitis A" and that antiviral-drug prescription frequency may have been altered.

This information was incorrect. I based these statements on early, anecdotal evidence that I cannot fully support. I should have checked my sources more carefully. I regret the error, and take full responsibility for it. All other aspects of the News story are accurate.

I look forward to reporting, in a future paper, the benefits and downsides of the novel systematic approach to disease reporting that we are taking at RSVP, once we have accumulated a sufficiently large database. We are fortunate to have funding from the US Department of Energy to expand the project to multiple reporting sites in various clinical settings, including non-academic medical clinics and publichealth clinics on both sides of the Mexico-US border.

Alan P. Zelicoff

Sandia National Laboratories, PO Box 5800,

Albuquerque, New Mexico 87185, USA 